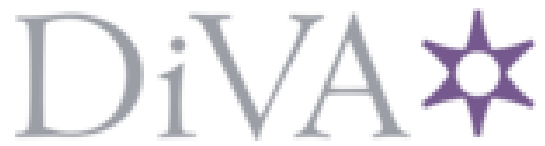

http://www.diva-portal.org

This is the published version of a paper published in Energy \& Fuels.

Citation for the original published paper (version of record):

Strandberg, A., Skoglund, N., Thyrel, M., Lestander, T A., Broström, M. et al. (2019) Time-Resolved Study of Silicate Slag Formation During Combustion of Wheat Straw Pellets

Energy \& Fuels, 33(3): 2308-2318

https://doi.org/10.1021/acs.energyfuels.8bo4294

Access to the published version may require subscription.

N.B. When citing this work, cite the original published paper.

Permanent link to this version:

http://urn.kb.se/resolve?urn=urn:nbn:se:umu:diva-157725 


\title{
Time-Resolved Study of Silicate Slag Formation During Combustion of Wheat Straw Pellets
}

\author{
Anna Strandberg, ${ }^{\dagger \oplus}$ Nils Skoglund, ${ }^{\dagger \oplus}$ Mikael Thyrel, ${ }^{\dagger,}$ Torbjörn A. Lestander, ${ }^{\ddagger}$ Markus Broström, ${ }^{*}, \dagger \oplus$ \\ and Rainer Backman ${ }^{\dagger}$ \\ ${ }^{\dagger}$ Department of Applied Physics and Electronics, Thermochemical Energy Conversion Laboratory, Umeå University, SE 90187 \\ Umeå, Sweden \\ ${ }^{*}$ Department of Forest Biomaterials and Technology, Swedish University of Agricultural Sciences, SE 90183 Umeå, Sweden
}

\section{Supporting Information}

\begin{abstract}
Ash formation during single-fuel pellet combustion of wheat straw at 700 and $1000{ }^{\circ} \mathrm{C}$ was studied throughout fuel conversion by quench cooling and analysis at different char conversion degrees. The combination of $\mathrm{X}$-ray microtomography analysis and scanning electronic microscopy with energy-dispersive X-ray spectroscopy showed that ash accumulated in rigid net structures at $700{ }^{\circ} \mathrm{C}$ with streaks or small beads surrounding the char, and the pellet mostly maintained its size during the entire fuel conversion. At $1000{ }^{\circ} \mathrm{C}$, the ash formed high-density melts that developed into bubbles on the surface. As the conversion proceeded, these bubbles grew in size and covered parts of the active char surface area, but without entirely blocking the gas transport. The successive char conversion dissolved increasing amounts of calcium in the potassium silicate melts, probably causing differences in the release of potassium to the gas phase. Similarities were found with slag from a combustion experiment in a domestic boiler, with regard to relative composition and estimated and apparent viscosity of the slag. Complete char encapsulation by ash layers limiting char burnout was not found at the single pellet level, nor to any greater extent from the experiment performed in a small domestic boiler.
\end{abstract}

\section{INTRODUCTION}

The focus on bioenergy as an alternative to fossil fuels has increased in recent years, and that has caused significant interest in the utilization of a broad base of lignocellulosic feedstock. An example is the increased use of residuals from the production of agricultural crops, corresponding globally to about $6700 \mathrm{Tg} /$ year. ${ }^{1}$ Straw from wheat constitutes about $18 \%$ and, together with residues from maize, rice, sugarcane, and soybean, these residuals make up about $95 \%$ of the global production of agrocrop residues. ${ }^{2}$

Decades of studies and industrial experience have shown that when using such agrocrop residues as fuel, one of the main challenges for combustion is ash-related problems, especially for the combustion of more ash-rich assortments. Most of the ash-forming elements are macro- and micronutrients that have essential biological functions, and the amounts and composition vary between different lignocellulosic feedstock and also between different parts of the plants. Herbaceous and agricultural biomass generally has a higher ash content and a greater variation in chemical composition than woody biomass. $^{3-8}$ Most importantly, straw and tall grasses have large amounts of $\mathrm{Si}^{4,6}$ and they usually contain high amounts of $\mathrm{K}, \mathrm{Ca}$, and $\mathrm{Cl}$ as well. ${ }^{6,9}$ Furthermore, the fuels may also contain extraneous material such as soil contaminants originating from biomass harvesting and handling, which also contribute in the ash-formation reactions.

Many types of biomass combustion appliances are designed for fuels with low ash content, such as typical woody-type fuels. Combustion of more ash-rich biomass fuels can result in operational problems and reduce boiler efficiency, with ash deposition on furnace walls and heat transfer surfaces, and in some cases also slag formation. ${ }^{10-13}$ The extent of the problems is largely dependent on the composition of ashforming elements in the fuel. Increased knowledge of ash transformation reactions and the formation of melts during fuel conversion increases the possibility of predicting and preventing ash-related problems, reducing particle emissions, and increasing combustion efficiency.

The amounts and types of slag compounds formed are dependent both on the combustion temperature and the relative composition of inorganic elements. Efforts at establishing fuel indexes describing ash-forming reactions in relation to release and slag formation have been published, e.g., silicon and chlorine contents have been found to be important in determining the release and capture of alkali, causing aerosol and slag formation. ${ }^{11,14-16}$ Straw-based fuels, which are typically rich in silicon and alkali and have a lower relative content of alkaline earth metals, generally display high slagging tendencies due to the formation of ash containing alkali silicates with relatively low melting temperatures. ${ }^{11,17}$ Moreover, slagging tendencies are related not only to ash melting but also to the viscosity of the melted or semi-melted ash. ${ }^{19}$ Also, important for the combustion of fuels rich in silicon and potassium is the presence of calcium and magnesium, which generally increase ash-melting temperatures and thus reduce slagging tendencies. ${ }^{11,15,17,18}$ Although approaches exist to describe slagging behavior using mainly thermodynamic equilibrium models and empirical observations, slag formation

Received: December 12, 2018

Revised: February 18, 2019

Published: February 21, 2019 
is poorly understood on a fuel particle level for agricultural biomass.

Time-resolved data on structural and compositional transformation during combustion of small char particles produced from switchgrass at temperatures mostly relevant for coal $(1600 \mathrm{~K})$ have shown that concentrations of ash-forming matter accumulated on the char surface, both as a result of carbon consumption and the migration of volatile inorganic elements to the surface. Furthermore, potassium was detected in the silicon-rich surface at intermediate stages of combustion, but as the conversion proceeded, potassium was found to be continuously replaced by calcium as the dominating cation in the mixed silicate, releasing potassium to the gas phase. ${ }^{19}$ Others have also described this evaporation mechanism of potassium as an effect of dissolving calcium (or magnesium) in the melt. ${ }^{15,18}$ The mechanism is supported by the high thermodynamic affinity of silicate melts for alkali earth metal oxides. $^{18}$

An overview of physical changes during pellet combustion, including char conversion and ash formation, was provided by the authors of the present paper in a recent publication. ${ }^{20}$ In that first-ever study using microtomography for ash-formation studies, differences between wheat straw (the same fuel as in the present paper) and poplar was visualized, clearly showing differences between the melting silicate ash of the straw fuel and the dry oxide/carbonate ash of the poplar fuel. It was also shown how cavities developed in the pellet during conversion. The objective of the present study was to provide a more detailed description of ash formation, structure, and composition during the combustion of wheat straw pellets at process temperatures relevant for biomass. Such a phenomenological description aims to complement conclusions drawn exclusively from inorganic reactions at equilibrium, since availability and reaction rates are affected by parameters such as the presence of converting char and the influence of reaction heat on temperature distribution in the pellet. Char samples were prepared by interrupted combustion experiments in a setup for isothermal thermogravimetric analysis (TGA) at a single pellet scale. Three-dimensional (3D) images were obtained by X-ray microtomography, showing the geometrical structure and morphology. Elemental composition of the chars and morphology of slag samples was analyzed by scanning electron microscopy with energy-dispersive X-ray spectroscopy (SEM-EDS). Detailed single-pellet SEM-EDS results concerning the morphology and composition were compared with observations from full-scale combustion environment, in this case a domestic boiler, and implications for large-scale facilities are discussed.

\section{EXPERIMENTAL SECTION}

2.1. Fuel Analysis. Pellets of straw from wheat (Triticum aestivum L.) with a diameter of $6 \mathrm{~mm}$ were used in the present study. Length was adjusted until the pellets weighed $600 \pm 30 \mathrm{mg}$. Fuel properties and elemental composition of the fuel are presented in Table 1 , analyzed with standard fuel analysis: moisture content (EN 14774/ 15414), ash content (EN 14775:2009/15403:2011), content of volatile matter (EN 15148:2009/15402:2011), main elements C, H, $\mathrm{O}$, and N (EN 15104:2011/15407:2011), and main ash-forming elements (EN 187185, 187177, and inductively coupled plasma atomic emission spectroscopy analysis of elements dissolved in $\left.\mathrm{LiBO}_{2} / \mathrm{HNO}_{3}\right)$.

2.2. Combustion Experiments. 2.2.1. Large-Sample Thermogravimetric Analysis. A laboratory-scale furnace for single-pellet-scale TGA was used in the present study. The equipment was recently
Table 1. Fuel Properties and Composition Including the Main Ash-Forming Elements

\begin{tabular}{lc} 
& wheat straw pellets \\
moisture $($ wt $\%)$ & 8.5 \\
ash $\left(\right.$ wt $\left.\%_{\text {d.b. }}{ }^{2}\right)$ & 4.3 \\
volatiles $\left(\right.$ wt $\left.\%_{\text {d.b. }}\right)$ & 77.5 \\
Main Elements $\left(\right.$ wt $\left.\%_{\text {d.b. }}\right)$ & \\
C & 47.5 \\
H & 5.8 \\
N & 0.4 \\
O & 42.0 \\
Main Ash-Forming Elements $\left(\mathrm{mg} / \mathrm{kg}_{\text {d.b. }}\right)$ & \\
K & 8450 \\
Ca & 2860 \\
Mg & 767 \\
Fe & 117 \\
Al & 145 \\
Si & 9460 \\
P & 638 \\
S & 717 \\
Cl & 2090 \\
a d.b. dry basis. & \\
\hline & \\
\hline
\end{tabular}

described elsewhere ${ }^{20-22}$ and is only briefly summarized here. The reactor (Figure 1) consists of an electrically heated furnace (internal dimension of $200 \times 130 \times 130 \mathrm{~mm}^{3}$ ) with a quenching tower. The furnace was equipped with an analytic balance with a resolution of 1 $\mathrm{mg}$, enabling the use of the furnace as a large-sample TGA. The pellet was placed in a platinum mesh basket (platinum gauze, 52 mesh, woven from $0.1 \mathrm{~mm}$ wire) hanging by a wire from the balance. Two different temperatures were used, 700 and $1000{ }^{\circ} \mathrm{C}$. Preheated air

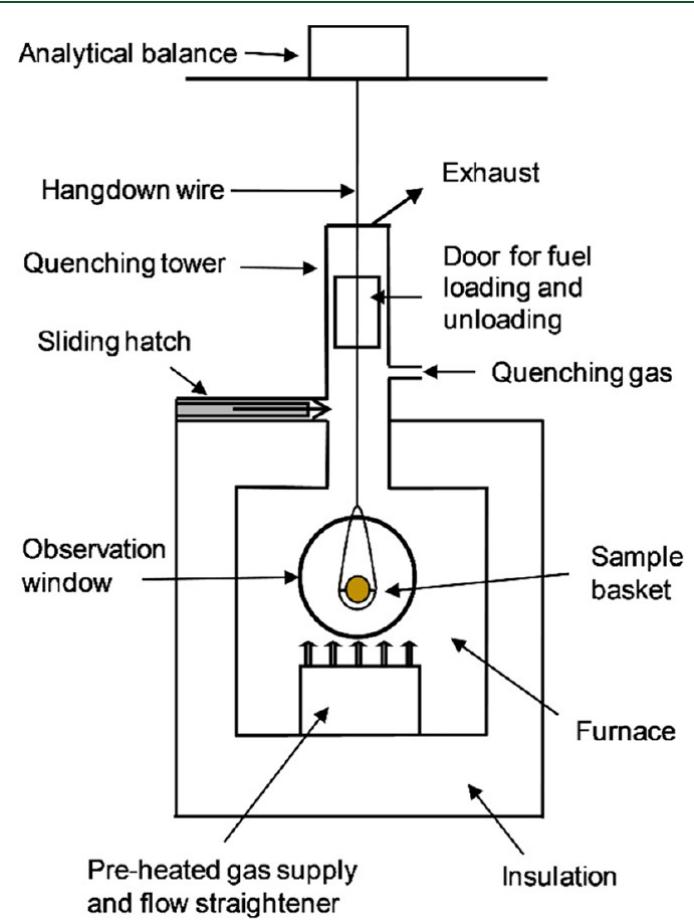

Figure 1. Schematic sketch of the large-sample TGA. Reprinted from Fuel Processing Technology, 176 (2018), Anna Strandberg, Mikael Thyrel, Nils Skoglund, Torbjörn A. Lestander, Markus Broström, Rainer Backman, Biomass pellet combustion: Cavities and ash formation characterized by synchrotron X-ray microtomography, Page 213, Copyright (2018), with permission from Elsevier. 

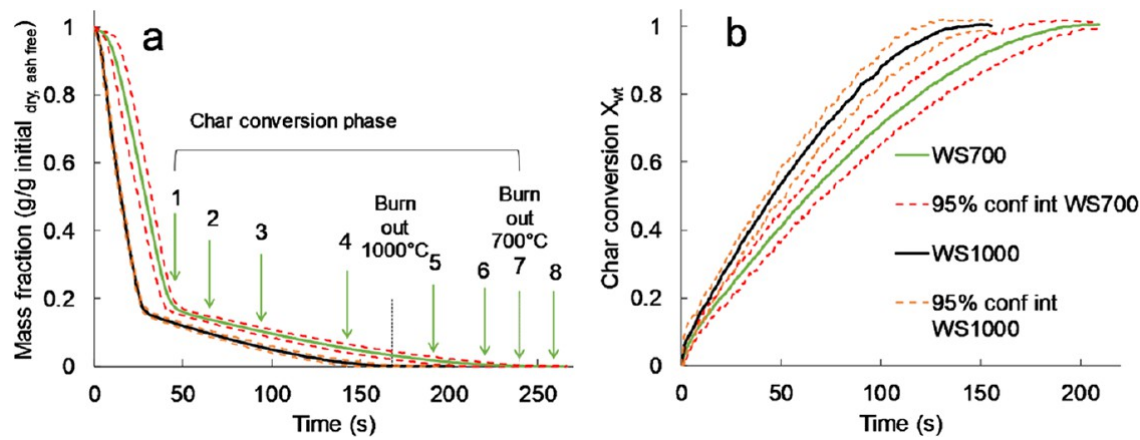

Figure 2. Conversion of wheat straw pellet during combustion at 700 and $1000{ }^{\circ} \mathrm{C}$ in the large-sample TGA. (a) Mass fraction on an ash-free basis with quenching points for the $700{ }^{\circ} \mathrm{C}$ experiments marked with arrows. (b) The char conversion with the time defined from when the char conversion phase starts for the respective temperature. Dotted lines indicate a $95 \%$ confidence interval. Parts of data have previously been presented in another publication. ${ }^{20}$

with a flow of $15 \mathrm{~L} / \mathrm{min}$ was supplied to the bottom of the furnace through a flow straightener. Hot air velocities were approximately 0.42 $\mathrm{m} / \mathrm{s}$ at $700{ }^{\circ} \mathrm{C}$ and $0.55 \mathrm{~m} / \mathrm{s}$ at $1000{ }^{\circ} \mathrm{C}$, creating a flow well within the laminar region around the burning pellet. The quenching gas was $\mathrm{N}_{2}$ with a flow of $3 \mathrm{~L} / \mathrm{min}$. The reactor moved vertically up and down to position the sample either in the isothermal heating zone or in the quenching tower, which were separated by a sliding hatch. Samples from interrupted and completed combustion were prepared, and 12 replicates with complete combustion were produced for each temperature. There were no sign of ash loss through the mesh during the experiments.

For the experiments with a furnace temperature of $700{ }^{\circ} \mathrm{C}$ (WS700), a period of drying and initial devolatilization was observed, followed by flaming devolatilization. It took approximately $8 \mathrm{~s}$ until visible pellet ignition for the $700{ }^{\circ} \mathrm{C}$ experiments. With the furnace temperature set to $1000{ }^{\circ} \mathrm{C}$ (WS1000), the pellet immediately ignited when it entered the hot atmosphere. The char conversion phase was defined from flame extinction until the glowing char faded. Average conversion curves were calculated with a normalized mass fraction $(\mathrm{g} /$ $\mathrm{g}$ initial) on an ash-free basis, and a $95 \%$ confidence interval was calculated based on the assumption of normal error distribution. The obtained char and ash samples were stored in a desiccator between combustion experiments and subsequent analysis.

To enable a detailed study of the char conversion and ash formation during the combustion, pellets were quenched at 8 different points. The first quenching point corresponds to the end of the devolatilization phase, and the last point after the end of the char conversion phase, corresponding to $110 \%$ of the time for the char conversion phase. The quenching times for the desired degrees of char conversion were estimated by first determining the reaction times required to complete the volatilization phase (indicated by point 1 in Figure 2) and for full char conversion (indicated by point 7 in Figure $2)$. Based on this data, char conversion for a specific pellet $n$ quenched at time $t\left(X_{n, \mathrm{wt}}\right)$ was calculated as follows

$$
X_{n, \mathrm{wt}}=\left(M_{n, 0}-M_{n, t}\right)\left(M_{n, 0}-M_{n, \text { residue }}\right)^{-1}
$$

where $M_{n, 0}$ is the sample mass of pellet $n$ at the start of the char conversion and $M_{n, t}$ is the mass at any time $t$ during char conversion. $M_{n, \text { residue }}$ is calculated from the original weight of pellet $n$ multiplied by the average mass fraction of residue after full char conversion based on 12 pellets at the respective reaction temperature.

It is well known (but not monitored in the present study) that the combustion temperature of a pellet is higher than the isothermal furnace temperature. Fagerström et al. ${ }^{22}$ tested the combustion temperature of single pellets by inserting a thermocouple in pellets, with an atmosphere of $10 \mathrm{vol} \% \mathrm{O}_{2}$, the maximum temperature during conversion reached approximately $900{ }^{\circ} \mathrm{C}$ at a furnace temperature of $700{ }^{\circ} \mathrm{C}$, and correspondingly $1100{ }^{\circ} \mathrm{C}$ when the furnace temperature was set to $1000{ }^{\circ} \mathrm{C}$. They also found that the pellet temperature reached a maximum (or close to maximum) at the beginning of the char conversion and stayed relatively constant until the end of the char conversion phase, when the temperature decreased to the furnace temperature. ${ }^{22}$ We used air when pellets were combusted in the largesample TGA, and therefore, the temperature inside the pellet was probably slightly higher compared to the study mentioned, but in the present study no effort was made to monitor the exact temperatures; instead, the isothermal reactor temperatures were used for notation.

2.2.2. Domestic Boiler. A combustion experiment with wheat straw pellets was performed in a domestic pellet boiler to generate a slag that could be compared to those of the single-pellet experiments. The under-fed burner was manufactured by EcoTec (Sweden) and has a maximum nominal power output of $20 \mathrm{~kW}$. The burner was installed in a reference boiler (Combifire, Sweden) of the type used for national certification tests of domestic pellet burners in Sweden and used in several earlier studies. ${ }^{17,23}$ The experiment was performed at $\sim 14 \mathrm{~kW}$ with excess air resulting in $14 \% \mathrm{O}_{2}$ in the flue gas and was interrupted after approximately $3 \mathrm{~h}$ due to severe slag build-up that prevented further operation. Samples were collected after cooling the boiler to room temperature.

2.3. X-ray Microtomography and Image Analysis. Analysis of the chars and corresponding char residues with $\mathrm{X}$-ray microtomography were performed using different experimental setups. The X-ray images for the WS700-5 and WS700-7 were acquired at the $\mathrm{X}$-ray facility at the Department of Soil and Environment at the Swedish University of Agriculture (Uppsala, Sweden). The wheat straw pellets were placed inside a sample holder with a $1 \mathrm{~mm}$ thick aluminum wall, which acted as an optical filter to reduce beamhardening artifacts. A GE $v \mid$ tomel $\times 240$ with a tungsten target and a GE 16" flat-panel detector with $2024 \times 2024$ detector crystals was used. The images had a resolution of $6.2 \mu \mathrm{m}$ in all directions. They were reconstructed from 2000 radiographs using the GE software datos $\mid \times$. They were collected from regular angular intervals during a $360^{\circ}$ rotation of the samples. Each radiograph corresponded to the average of 6 obtained with an exposure time of $133 \mathrm{~ms}$ at a tube voltage of $90 \mathrm{kV}$ and an electron flux of $60 \mu \mathrm{A}$.

Analyses with synchrotron-based hard X-ray microtomography was performed at Beamline 8.3.2 at Advanced Light Source (ALS) (Lawrence Berkeley National Laboratory (LBNL), Berkeley, California) for the WS1000 chars. The experimental setup is described in more detail elsewhere. ${ }^{24-26} \mathrm{X}$-ray energy of $20 \mathrm{keV}$ was used. The sample was glued and/or taped to a kinematic mount, which in turn was attached to a rotation stage. The sample was rotated $180^{\circ}$, with an angular step of $0.175^{\circ}$, giving a total of 1025 projections. The images were collected with a CCD camera (PCO Edge with $2560 \times 2160$ pixels) with a lens with magnifications of $2 \times$. The camera had an exposure time of $300 \mathrm{~ms}$, resulting in 30000 counts on the camera. This resulted in a pixel size of $3.25 \mu \mathrm{m}$ and an $8.3 \mathrm{~mm}$ horizontal field of view. The tomographic reconstructions were performed with an in-house software algorithm developed at LBNL.

The scanned image was analyzed using differences in X-ray absorption caused by differences in density and atomic number $Z$ of 


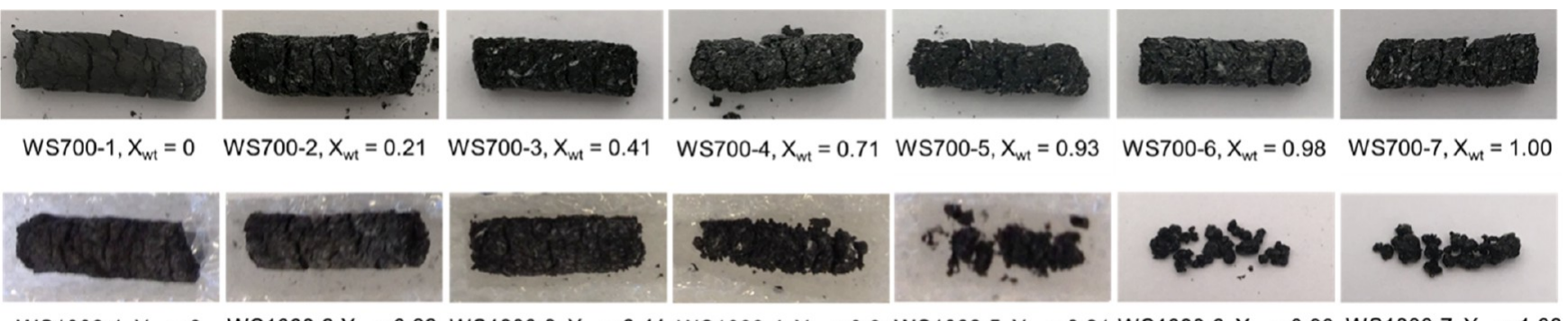

$W S 1000-1, X_{w t}=0 \quad W S 1000-2, X_{w t}=0.22 W S 1000-3, X_{w t}=0.41 W S 1000-4, X_{w t}=0.6 W S 1000-5, X_{w t}=0.91 W S 1000-6, X_{w t}=0.98 W S 1000-7, X_{w t}=1.00$

Figure 3. Chars produced at $700{ }^{\circ} \mathrm{C}$ (WS700) and $1000{ }^{\circ} \mathrm{C}$ (WS1000) at quenching points 1-7. Reprinted in parts from Fuel Processing Technology, 176 (2018), Anna Strandberg, Mikael Thyrel, Nils Skoglund, Torbjörn A. Lestander, Markus Broström, Rainer Backman, Biomass pellet combustion: Cavities and ash formation characterized by synchrotron X-ray microtomography, Page 215, Copyright (2018), with permission from Elsevier.

the elements in the object scanned. The value of the dimensionless $\mathrm{X}$ ray absorption coefficient (or attenuation coefficient), $\mu$, reflects the sample's optical density in each voxel and was calculated from the $\mathrm{X}$ ray absorption at different projections.

With the software packages Fiji (Fiji Is Just ImageJ) and Avizo 9.3 (Fei VSG Inc., Burlingham, MA), watershed segmentation and surface-rendering reconstructions of the reconstructed microtomography images were performed. The software packages were also used for the visualization of 3D tomographic volumes. The area of interest was identified for the sample, and the background was masked by subtraction. Segmentation was performed based on the absorption histogram, with threshold $<2.0 \mu$ for cracks or cavities, threshold 2.0$4.0 \mu$ for char matrix, and threshold $4.0-4.6 \mu$ for ash compounds. To analyze the radial shrinkage of the samples, an average diameter was calculated.

2.4. SEM-EDS Analysis. The morphology of the samples was characterized using variable-pressure scanning electron microscopy (VP-SEM; Carl Zeiss Evo LS-15), using a backscattered electron detector at an accelerating voltage of $15 \mathrm{kV}$ and a probe current of 300-400 pA. The elemental composition was quantified using an energy-dispersive X-ray spectrometer (EDS; Oxford Instruments XMax $80 \mathrm{~mm}^{2}$ ). These analyses were performed at Umeå Core Facility for Electron Microscopy (UCEM), Chemical Biological Centre (KBC), Umeå University (Umeå, Sweden).

The charred pellets and the wheat straw residues were embedded in epoxy, and dry-polished with silicon carbide paper to prepare cross sections for analysis. Parts of the residue from the domestic pellet boiler were also prepared for surface and cross sectional analysis. For the cross section analysis, different parts (sites) of the samples were analyzed. More than 5 point or area analyses were performed on each site, which gives in total at least 15 analyses, which are the basis for the average values that are presented. The compositional information was only summarized from areas containing dense, accumulated ash; signal-to-noise levels and concentrations were too low to accurately quantify any ash components dispersed in the char structure. Chlorine was excluded from the EDS analysis for two reasons; the epoxy resin contains chlorine and thus provides a background signal, making the quantification of low amounts impossible. Furthermore, chlorine is readily volatilized during combustion and is thus not expected to remain to any greater extent even in the $700{ }^{\circ} \mathrm{C}$ samples due to the actual temperatures being slightly higher than $900{ }^{\circ} \mathrm{C}$ during fuel conversion of the pellets. ${ }^{27}$

2.5. Thermodynamic Equilibrium Modeling. Thermodynamic equilibrium modeling was employed to estimate the melt fraction and composition in the molten ashes formed during char conversion. The viscosity of the molten fraction was estimated based on the relative compositions of $\mathrm{SiO}_{2}, \mathrm{CaO}, \mathrm{MgO}$, and $\mathrm{K}_{2} \mathrm{O}$ for the low-temperature with respect to high-temperature scenario mentioned below. The software FactSage 7.1, ${ }^{28,29}$ with the databases FactPS, FT Oxide, and FT Salt were used to perform the melt fraction estimations. Viscosities were estimated using the viscosity toolbox in FactSage 7.1 with Glasses database. ${ }^{30-32}$
A linear correlation fit of SEM-EDS analysis results was performed to estimate the main ash-forming elemental composition for thermodynamic equilibrium modeling. This linear fit was based on quenching points 3-8 (Figure 2) for both temperatures, results from the SEM-EDS analysis of the ash surrounding the char, and on the char residue after full conversion (Figure S1, Supporting Information). The end points from the linear fits are hereinafter denoted LT1 and LT2 (for low temperature) and HT1 and HT2 (for high temperature), where index 1 corresponds to low char conversion $(\sim 40$ wt $\%)$ and index 2 to full conversion.

\section{RESULTS AND DISCUSSION}

3.1. Time-Resolved Fuel Conversion. Pellets were quenched at 8 different points to enable a detailed study of the char conversion and ash formation during the combustion, as indicated by arrows for the $700{ }^{\circ} \mathrm{C}$ experiments in Figure 2, with a complete list for both temperatures in Table 2 .

Table 2. Quenching Points with Time and Char Conversion Degree for Different Temperatures

\begin{tabular}{ccccc}
$\begin{array}{c}\text { quenching } \\
\text { point }\end{array}$ & $\begin{array}{c}\text { time }(\mathrm{s}) \\
\text { WS700 }\end{array}$ & $\begin{array}{c}X_{\mathrm{wt}} \\
\text { WS700 }\end{array}$ & $\begin{array}{c}\text { time }(\mathrm{s}) \\
\text { WS1000 }\end{array}$ & $\begin{array}{c}X_{\mathrm{wt}} \\
\text { WS1000 }\end{array}$ \\
1 & 53 & 0 & 29 & 0 \\
2 & 73 & 0.21 & 43 & 0.22 \\
3 & 102 & 0.41 & 64 & 0.41 \\
4 & 150 & 0.71 & 98 & 0.68 \\
5 & 199 & 0.93 & 133 & 0.91 \\
6 & 228 & 0.98 & 154 & 0.98 \\
7 & 247 & 1.00 & 168 & 1.00 \\
8 & 267 & N.A. & 182 & N.A. \\
\hline
\end{tabular}

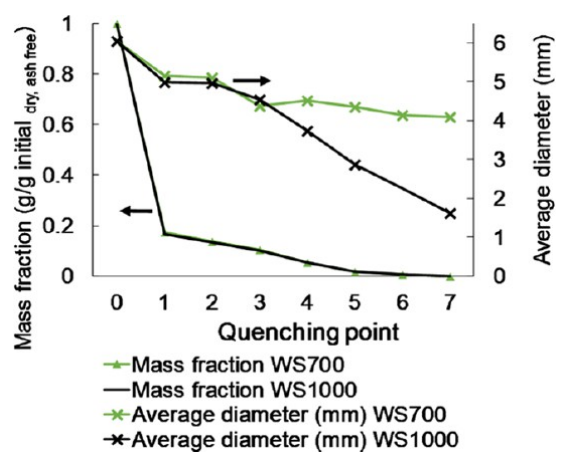

Figure 4. Char conversion degree (mass fraction) and average diameter for the quenching points. Parts of data have previously been presented in another publication. ${ }^{20}$ 

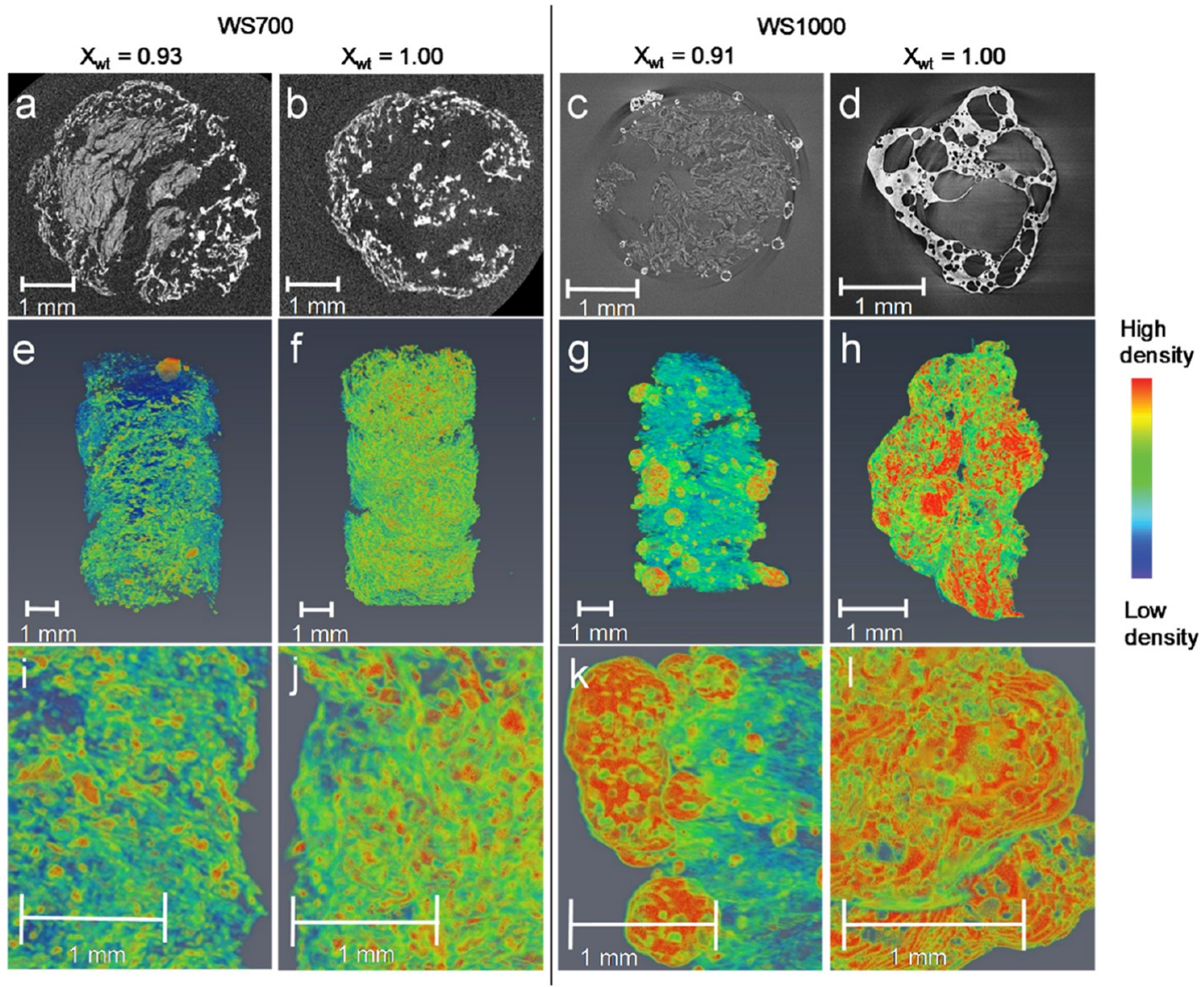

Figure 5. Cross section of (a) WS700-5 quenched at $X_{\mathrm{wt}}$ 0.93; (b) WS700-7 at full conversion; (c) WS1000-5 quenched at $X_{\mathrm{wt}} 0.91$; and (d) WS1000-7 at full conversion. Three-dimensional reconstructions with color mapped by X-ray absorption (density), from 2.0 to $4.6 \mu$, of the same chars: (e) WS700-5; (f) WS700-7; (g) WS1000-5; and (h) WS1000-7. (i-l) Parts of the same 3D reconstructed chars are magnified. The 3D reconstructions can also be found as animation (Video 1 , electronic version only).

Already by visual inspection, it was clear that the wheat straw char conversion was affected by the different combustion temperatures as seen in Figure 3, which show chars from different quenching points. The differences were distinct with varying shrinking behavior between the WS700 and WS1000 samples after quenching point 2, as shown in Figure 4. The diameters of WS1000 chars were estimated in an earlier published work $^{20}$ and are used here for comparison with WS700 chars, for which the diameters were measured from photographs of the chars. WS700 kept its outer diameter quite constant, whereas WS1000 shrank continuously after quenching point 2, leaving only fragmented ash samples for quench points 7 and 8. Fragments from quenching point 5 and 6 shown in Figure 3 were formed during handling of the brittle char.

3.2. Three-Dimensional Morphology and Char Conversion. 3.2.1. X-ray Tomography. Figure 5 shows detailed grayscale cross-sectional images from quenching point 5 (Figure 5a,c) and point 7 (Figure 5b,d) from the 700 and $1000{ }^{\circ} \mathrm{C}$ combustion experiments, respectively. Bright spots correspond to ash clusters (high optical densities) and fully black spots represent voids. The dark ring-shaped shadows in Figure $5 \mathrm{c}, \mathrm{d}$ are reconstructional artefacts, and the dark parts in the corners of Figure 5a,b are outside the image. The reconstructed $3 \mathrm{D}$ volumes of the same chars are shown in Figure 5e,g (WS700/1000-5) and Figure 5f,h (WS700/1000-
7), and are also available as animations in Video 1 (electronic version only).

The samples from combustion at $700{ }^{\circ} \mathrm{C}$ contained apparently melted or partially melted ash visible as streaks or small beads in a rigid net structure surrounding the char (Figure 5a,b and e,f). The exact melt fraction of accumulated ash was not possible to evaluate by microtomography alone, but rounder shapes were interpreted as signs of increased melting. Magnified parts of the WS700 reconstructed chars show that more high optical density clusters are formed as char conversion continues (Figure $5 \mathrm{i}, \mathrm{j}$ ), caused by the accumulation of silicate-rich ash while largely maintaining fuel particle size and structure. For the $1000{ }^{\circ} \mathrm{C}$ samples, obvious melts were concentrated in bubbles, plausibly through melt formation, with apparently ash-free areas in between. The melt formed did not entirely cover the remaining char, forming a major oxygen diffusion barrier until possibly at the very end of conversion (Figure 5c,g). At full conversion, the remaining melted ash formed irregular shapes of agglomerated bubbles (Figure 51), but the apparent high viscosity maintained the porous structures. The more obvious shrinkage at WS1000-7 compared to WS700-7 was probably directly linked to the silicate ash formation and melting behavior.

3.2.2. Effect of Ash Formation on Char Conversion. With the aim of visualizing the influences of the ash-forming reactions on the char conversion rate, the char conversions are plotted versus a normalized time (normalized with $t$ at $X_{\mathrm{wt}}=$ 
0.5) in Figure 6. Any large differences related to, e.g., gas transport limitations by melted ash layers could be revealed by

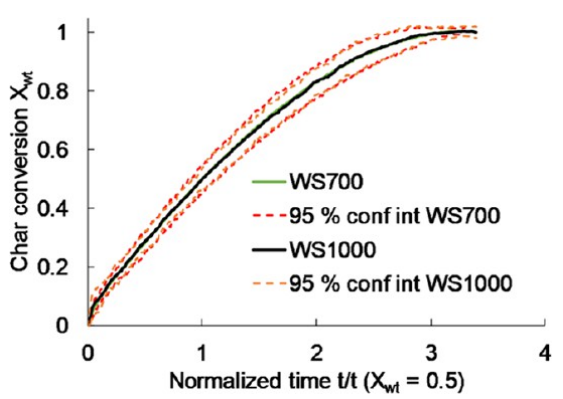

Figure 6. Char conversion, $X_{\mathrm{wt}}$ versus the time normalized with the time at $X_{\mathrm{wt}}=0.5$.

different curve shapes. Since the curves are almost identical, the possible effect of prohibition of contact between the char and the oxidation agent by silicate melts seems to be similar for different temperatures, despite the large differences observed in ash layer appearance and properties.

Char encapsulation by ash layers that limit the char burnout has been seen in an earlier study of gasification of powder from wheat straw char. ${ }^{33}$ At a single-pellet level, this complete encapsulation was not found, nor for the experiment in a small domestic boiler to any greater extent. This suggests that the limitation of char burnout caused by ash layers encapsulating remaining char in powder gasification ${ }^{33}$ may be caused by a different mechanism than what is observed for larger fuel particles in the combustion regime, possibly related to either the atmospheres or to the physical differences between the fuels (particle volume, surface, and packing), determining where the formation of the sticky ash layer appeared. Importantly, the porous structures observed in the thicker ash layers (Figure 5k,l) seem to be sufficiently permeable for an effective char conversion despite the layer thickness. However, in industrial-scale grate-fired combustion, the fuel conversion may still be influenced by ash layers due to ash accumulation on the char bed surface causing very different conditions in various parts of the fuel bed.
3.3. Chemical Composition. Char cross sections were also analyzed by SEM-EDS. Figures 7 and 8 show the SEM images from different quenching points at 700 and $1000{ }^{\circ} \mathrm{C}$, respectively, visualizing the trends during the conversion seen earlier in the X-ray tomographic figures. No visible migration or accumulation of the ash-forming elements was observed for quenching points 1 and 2 . From quenching point 3 , at $X_{\mathrm{wt}}=$ 0.41 , visible amounts of accumulated ash started to form on the char surface for both temperatures. This corresponded to $100 \mathrm{~s}$ for WS700 and $60 \mathrm{~s}$ for WS1000 before any ash accumulation could be observed. There was a clear and rapid migration of the volatile ash-forming elements (i.e., mainly potassium for the present fuel), and for WS1000 (Figure 7), the ash was concentrated in these earlier-described silicon-rich bubbles with ash-free areas in between. Later during the conversion, and in agreement with tomography data, it appeared that the carbon matrix was not completely blocked for further oxidation by surrounding air.

SEM-EDS analysis was also used to provide information on the elemental composition of the ash. Figure 9 summarizes changes in relative composition of the main ash-forming elements in the ash accumulated around the char during fuel conversion and ash formation. Numbers are provided on a molar basis, and $\mathrm{Cl}$ is excluded due to its presence in the epoxy and expected low concentrations in the samples. Compositional differences in the ash should be considered indicative due to relatively large standard deviations (Figure 9) probably originating from variations between pellets, but the general trends show interesting patterns. The release of potassium seems to be relatively low for both temperatures, likely due to inclusion of $\mathrm{K}$ in silicates, which is more prevalent at higher temperatures, and in agreement with other studies. ${ }^{34}$ Slightly lower amounts of $\mathrm{K}$ and higher $\mathrm{Ca}$ could be observed in the ash at the higher temperature. Especially for the $700{ }^{\circ} \mathrm{C}$ experiments, $\mathrm{K}$ appears to decrease with conversion. Altogether, this could indicate that the equilibrium state was more rapidly reached for the $1000{ }^{\circ} \mathrm{C}$ samples, whereas the slower reactions at $700{ }^{\circ} \mathrm{C}$, probably involving a lower melt fraction, gave the trend that agrees with the idea of a K-silicate melt dissolving $\mathrm{Ca}$ and releasing $\mathrm{K}^{15,17,18}$

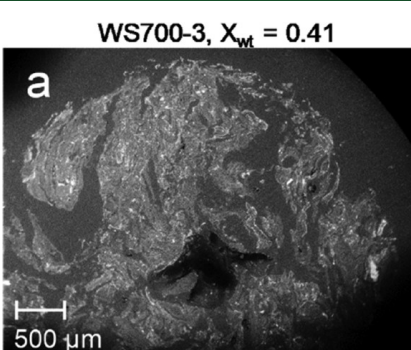

WS700-6, $X_{\text {wt }}=0.98$

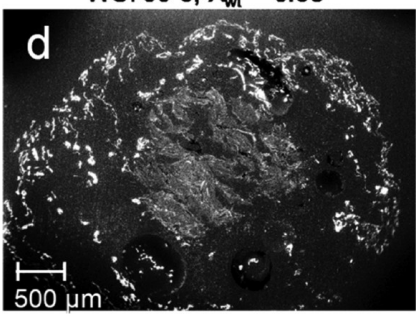

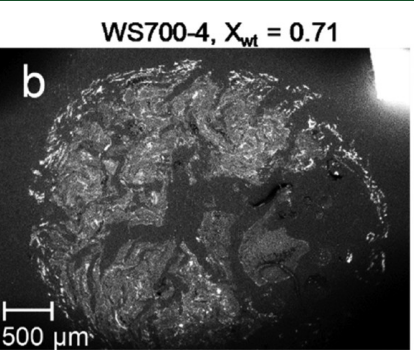

WS700-7, $x_{m}=1.00$

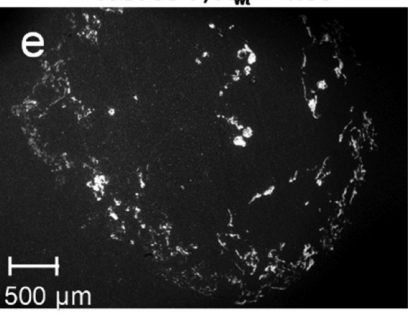

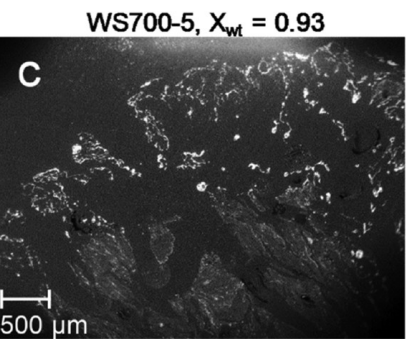

WS700-8, $x_{w t}=1.00$

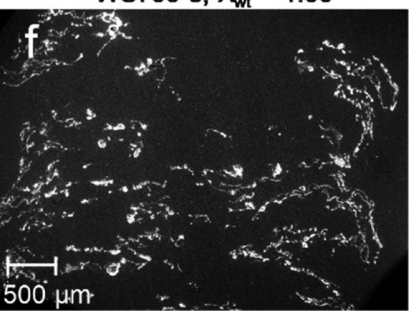

Figure 7. SEM micrographs of char and ash from combustion at $700{ }^{\circ} \mathrm{C}$ : (a) WS700-3 $X_{\mathrm{wt}}=0.41$, (b) WS700-4 $X_{\mathrm{wt}}=0.71$, (c) WS700-5 $X_{\mathrm{wt}}=$ 0.93, (d) WS700-6 $X_{\mathrm{wt}}=0.98$, (e) WS700-7 $X_{\mathrm{wt}}=1.00$, and (f) WS700-8 $X_{\mathrm{wt}}=1.00$. 

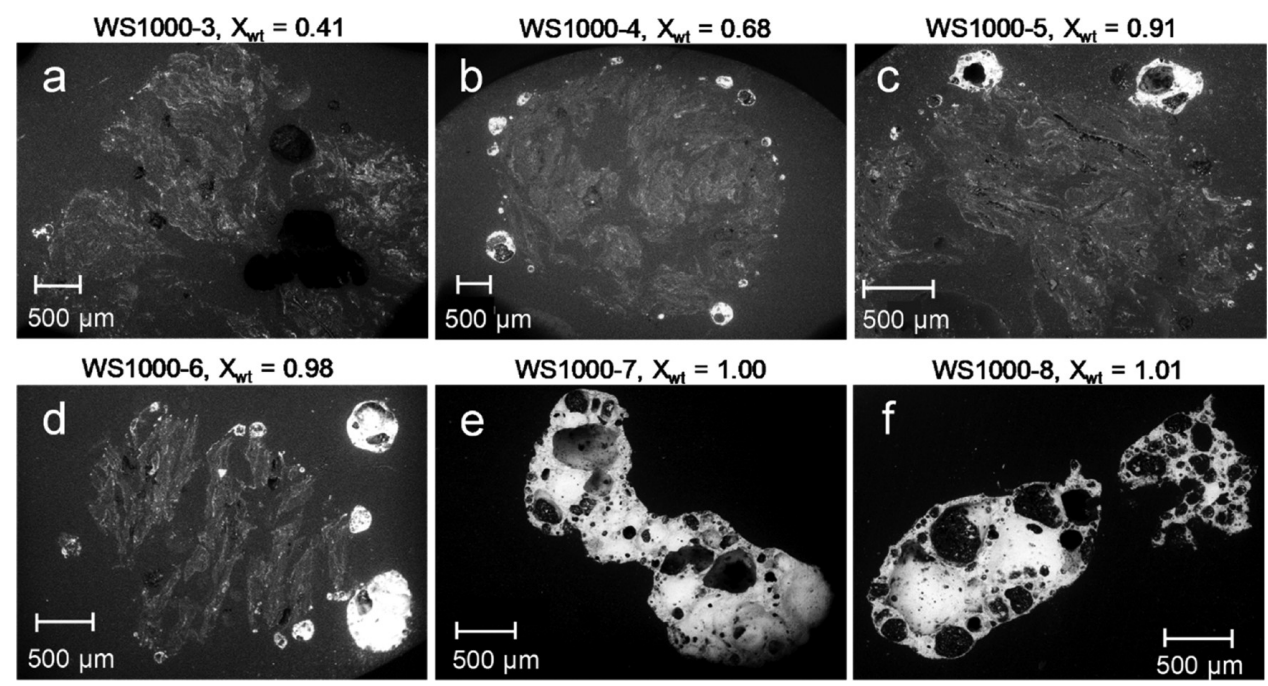

Figure 8. SEM micrographs of char and ash from combustion at $1000{ }^{\circ} \mathrm{C}$ : (a) WS1000-3 $X_{\mathrm{wt}}=0.41$, (b) WS1000-4 $X_{\mathrm{wt}}=0.68$, (c) WS1000-5 $X_{\mathrm{wt}}$ $=0.91$, (d) WS1000-6 $X_{\mathrm{wt}}=0.98$, (e) WS1000-7 $X_{\mathrm{wt}}=1.00$, and (f) WS1000-8 $X_{\mathrm{wt}}=1.01$.

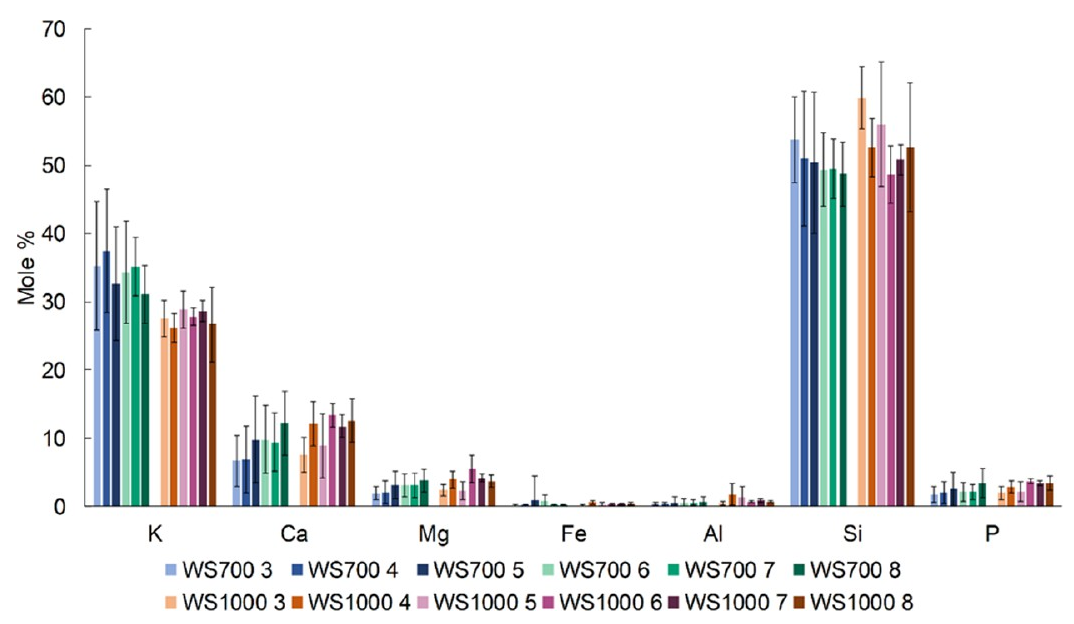

Figure 9. Relative composition of the main ash-forming elements in the ash surrounding the char (if any left). Error bars indicate the variation with 1 standard deviation.
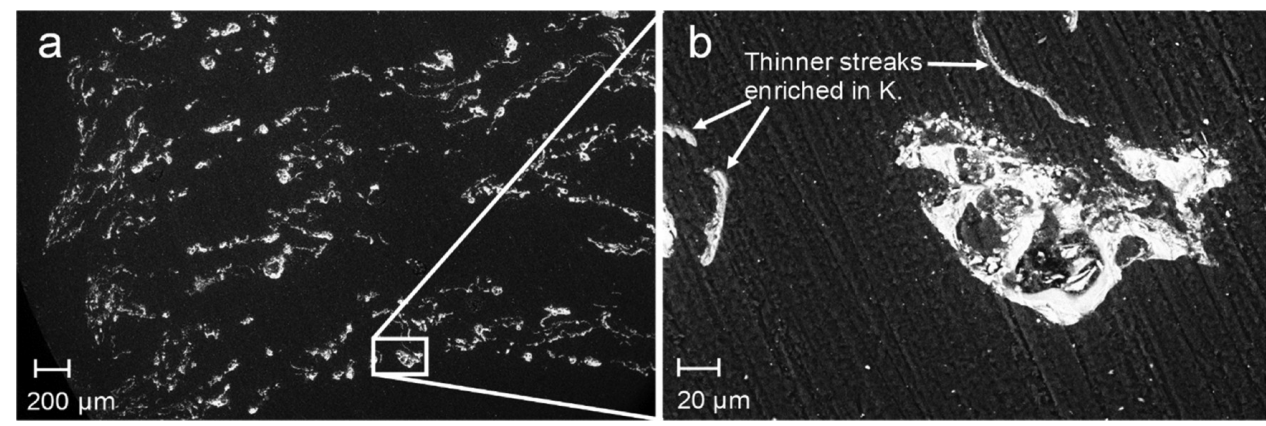

Figure 10. SEM micrographs of WS700-8. Examples of some variations in the ashes for $700{ }^{\circ} \mathrm{C}$ chars, where the thin streaks contain more $\mathrm{K}$.

In the ash structure of the $700{ }^{\circ} \mathrm{C}$ chars, thinner streaks assumed to be at least partial melts enriched in $\mathrm{K}$ compared to the rest of the ash (up to $40 \mathrm{~mol} \%$ of main ash-forming elements) were observed, and an example is illustrated in Figure 10. This kind of heterogeneity explains a part of the larger variation in the WS700 chars (the standard deviation in Figure 9).

Besides the ash formed on the outer surface of the char, SEM-EDS analysis also revealed an accumulation of ash compounds around the cavities in the interior parts of the charred pellets (Figure 11). From quenching point 3 (at $X_{\mathrm{wt}}=$ 0.41 ), there were $\mathrm{Si}$-rich ashes accumulated around the cavities that contained comparatively more Si and less Ca than the ash found surrounding the char, seen as bright spots in the figure (examples number with 1 in the figure). When the conversion continued, the number of ash accumulations around the cavities increased, and similar trends were seen closer to the surface, seemingly related to char conversion and/or oxygen 

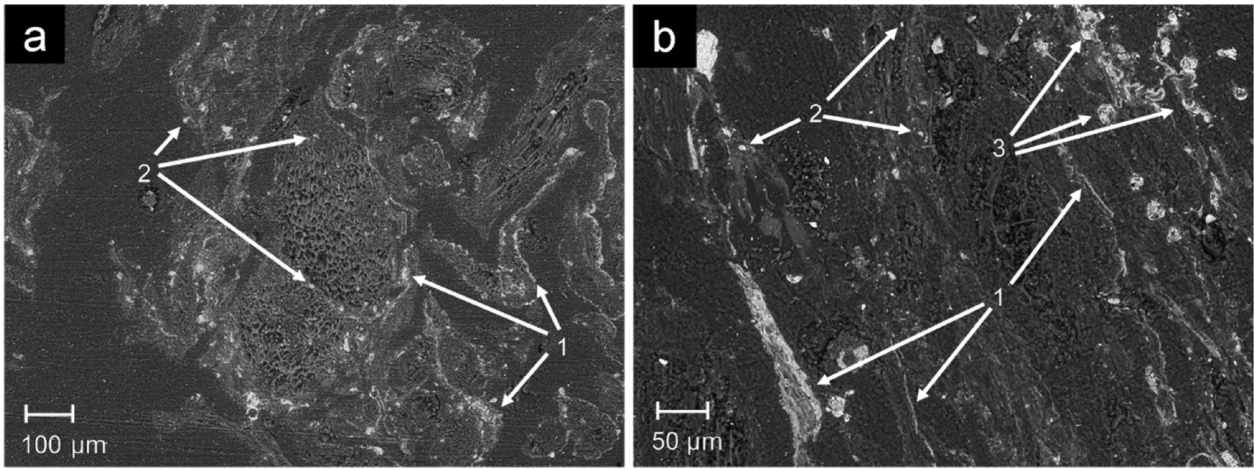

Figure 11. SEM micrographs showing the accumulation of denser compounds around the cavities in the interior part of the char, exemplified with cross sections of (a) WS1000-4 from the middle of the char, quenched at $X_{\mathrm{wt}} 0.68$, and (b) WS1000-5 quenched at $X_{\mathrm{wt}} 0.91$, zoomed in close to the outer surface. Number 1, example of accumulations around cavities. Number 2, example of probably phytoliths (silica) originating from the plant material of the fuel. Number 3, example of small bubbles developed closer to surface.
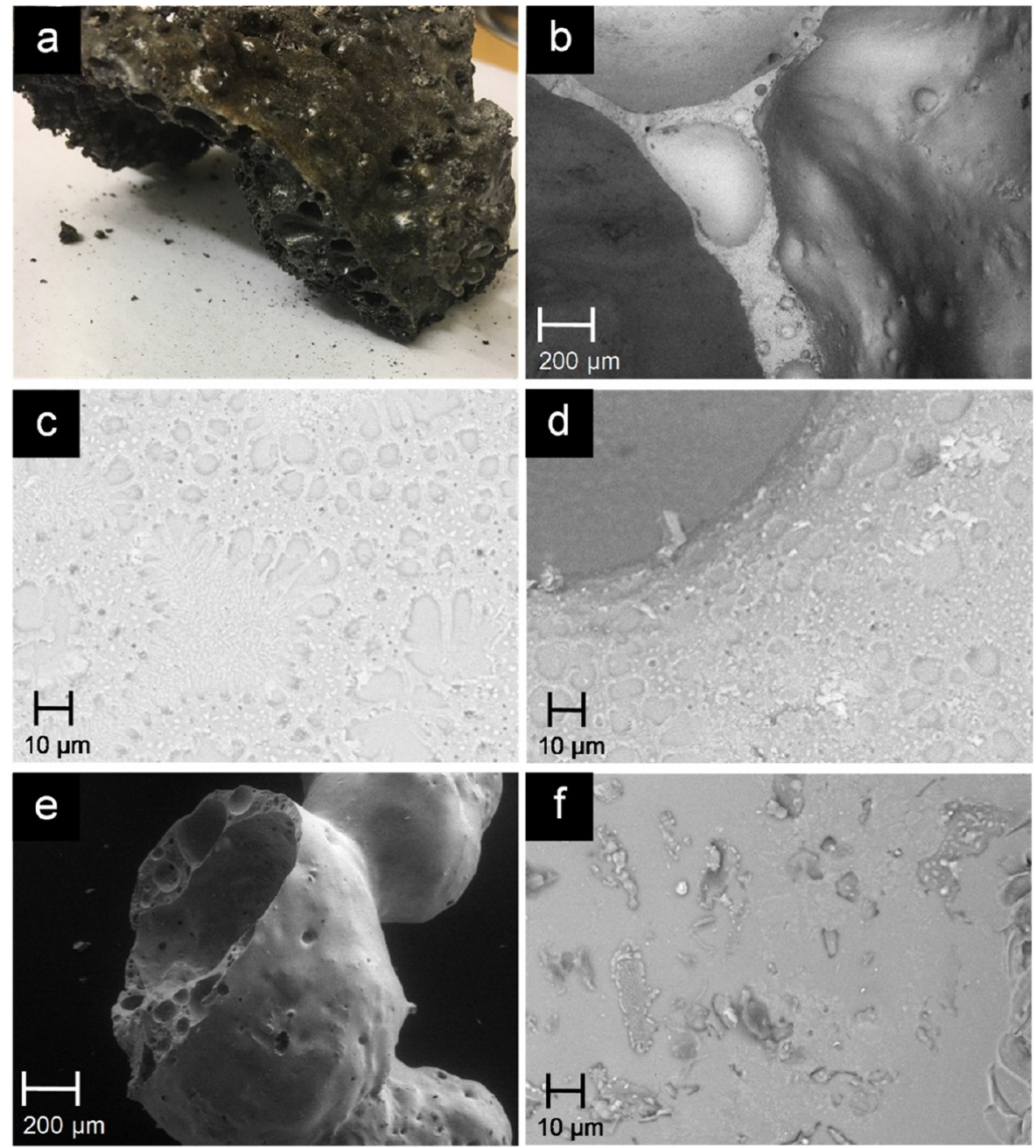

Figure 12. (a) Photograph of slag sample collected after wheat straw combustion in the domestic pellet boiler. (b) SEM micrograph of the slag cross section. (c) SEM micrograph zoomed in on the surface of a part of the slag. (d) SEM micrograph from the outside of the slag, zoomed in around a small hole. For comparison. (e) SEM micrograph of WS1000-7 (on carbon tape). (f) SEM micrograph of WS1000-7 surface.

availability. The composition of the accumulated ash became increasingly similar to that of the ash on the surface of the char when conversion proceeded, and closer to the surface. For the $1000{ }^{\circ} \mathrm{C}$ char, small bubbles developed at the cavities closer to the surface in the later part of conversion, similar to those found on the outer surface (examples number with 3 in Figure
$11 b)$. In addition, Si-rich bead-shaped particles were found distributed all over the inner part of the chars, especially at the early part of char conversion (seen as small bright spots in Figure 11, examples shown with number 2). They were probably phytoliths (silica) originating from the plant material of the fuel, ${ }^{35,36}$ gradually incorporated in the ash accumulations 
by reactions with $\mathrm{K}$ in the gas phase and/or by incorporation in melts.

The resulting slag residue from the combustion experiment in the domestic boiler was a hard lump of melted ash. Figure $12 \mathrm{a}$ shows a photograph of a piece of the lump, and Figure $12 \mathrm{~b}$ is an SEM image showing a cross section of the melt. Morphological similarities were observed when comparing to the WS1000 residues from the single-pellet combustion experiment, as visualized in Figure 12. The melted ash from both kinds of slag consisted of agglomerated bubbles with pores, in different sizes and irregular distribution (slag from the domestic boiler in Figure 12b and WS1000 char residues in Figure 12e). The SEM micrographs of slag surfaces from the domestic boiler (Figure 12c,d) and WS1000 char residues (Figure 12f) both show a dull gray background with a rather homogeneous composition.

Analyses with SEM-EDS showed similar relative compositions of the main ash-forming elements for the residue after combustion at the single pellet furnace, quenching point 8 (Figure 13), with no statistically significant differences. This

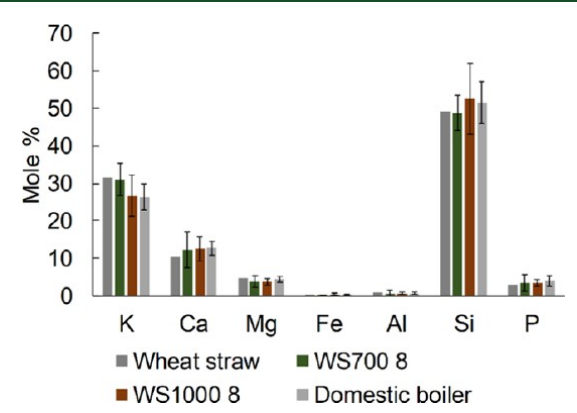

Figure 13. Relative composition of main ash-forming elements from SEM-EDS analyses of the wheat straw residues remaining at quenching point 8 and after combustion in the domestic pellet boiler. Error bars show 1 standard deviation. The wheat straw bars are the results from fuel analysis (Table 1).

result indicates that the single-pellet combustion can be a valuable tool for studying ash formation during conversion and can provide a way to connect subscale experiments with largescale applications.

3.4. Melt Fraction and Viscosity Estimations. The $\mathrm{SiO}_{2}$ concentration together with alkali content plays an important role in the viscosity, i.e., influencing the potential stickiness and the flow of the melt, and together with the melt fraction, viscosity has an effect on the slagging tendencies. ${ }^{17}$ The melt fraction calculations of the ash surrounding the char and for the ash residue after full conversion, estimated with FactSage modeling, indicated that for high temperature (HT, WS1000) almost all ashes were molten $(>0.9)$, whereas for lower temperature (LT, WS700), the melt fraction (on mole basis) was between 0.85 and 0.64 (Figure 14a). This seemed to be in qualitative agreement with the experimental observations.

The lower melt fraction at the end of char conversion for the LT scenario was caused by $\mathrm{K}$ depletion from the ash with increased conversion. For the HT case, the melt fraction was higher due to higher temperature, and more constant with conversion, since the $\mathrm{K}$ depletion was more rapid and almost completed already at the beginning of the char conversion phase.

The relative composition of $\mathrm{SiO}_{2}, \mathrm{CaO}, \mathrm{MgO}$, and $\mathrm{K}_{2} \mathrm{O}$ of the calculated melt fraction was used for the viscosity calculations. According to viscosity estimations using the viscosity toolbox in FactSage, the viscosities of the melted part of the ashes varied between 11800 and $12500 \mathrm{~Pa} \mathrm{~s}$ for LT (WS700) at $900{ }^{\circ} \mathrm{C}$ and between 340 and $680 \mathrm{~Pa} \mathrm{~s}$ for HT (WS1000) at $1100{ }^{\circ} \mathrm{C}$. Calculated viscosities are presented in Figure 14b, differences in viscosity for WS700 and WS1000 melts were mainly due to the strong temperature dependence. The HT2 case displays a lower viscosity than HT1, likely related to more dissolved $\mathrm{Ca}^{2+}$, which is known to decrease silicate melt viscosities. This decrease in viscosity is likely caused by the depolymerization effect, which is known to be stronger for Ca than for K. Estimated viscosity trends seem to be in qualitative agreement with the observations, since WS700 ash was rather stationary, whereas the lower viscosity of WS1000 allowed the formation of liquid and bubbles. Similarities were found with slag from the combustion experiment in a domestic boiler, where the calculated viscosity depends highly on the estimated temperature.

3.5. Implications. The results obtained by combining quenching during single-pellet conversion with spatial and chemical analyses show how mechanisms in various ashforming reactions can be investigated with the used approach. Studies of fundamental physiochemical transformations can be expanded to provide detailed information of the understanding of ash reactions crucial for the successful operation of industrial facilities. For instance, the use of fuel additives for particle emission reduction and slag formation has been extensively studied from laboratory scale to industrial scale, ${ }^{37-43}$ but studying the time-resolved fuel alkali absorption in additives could provide additional information on the reaction rates determined by alkali mobility and solid-gas
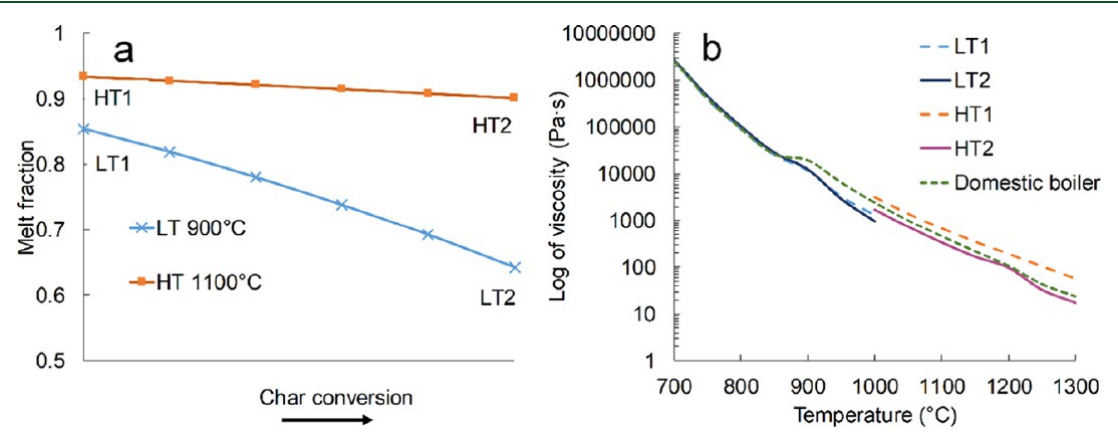

Figure 14. (a) Calculated melt fraction (on mole basis) for low-temperature with respect to high-temperature scenario (marks in the curve correspond to intermediate points) and (b) the viscosity of the melt for each point (logarithmic scale) together with the viscosity of the melted ashes from the domestic pellet boiler. 
reactions. This, in turn, could be useful for further development of coating or co-pelletizing strategies for additives, and potentially resulting in optimizing dosing strategies in industrial scale, thereby enabling lower costs for additive and ash removal. Another example are reactivities of various sulfurcontaining additives (e.g., elemental S or $\left.\left(\mathrm{NH}_{4}\right)_{2} \mathrm{SO}_{4}\right)$, which are known to react with gaseous alkali compounds. However, the effectiveness of sulfur additives varies between studies, ${ }^{4-46}$ single-pellet experiments combined with advanced diagnostics $^{4-49}$ could still provide new insights and improve the understanding of the underlying reaction mechanisms.

\section{CONCLUSIONS}

Rapid formation of $\mathrm{K} / \mathrm{Ca}$ silicates was observed, indicating large interaction between gaseous $\mathrm{K}$ compounds and silicon in the fuel. For different temperatures, there were indications of $\mathrm{K}$ depletion over time at $700{ }^{\circ} \mathrm{C}$, whereas $\mathrm{K}$ concentrations were near constant at $1000{ }^{\circ} \mathrm{C}$ and in line with pellet burner experiments. This suggests only part of $\mathrm{K}$ will volatilize in the presence of a reactive silicate matrix and that reaction temperature primarily increases volatilization rate rather than how much $\mathrm{K}$ will be retained in silicates. Further, the morphology and composition of ash produced in $1000{ }^{\circ} \mathrm{C}$ experiments was similar to ash from pellet burner experiments. Other specific observations are as follows:

- Fuel particle diameter was nearly constant during conversion at the lower temperature, although char conversion leaved voids encapsulated by thin streaks of ash.

- Ash morphology at $700{ }^{\circ} \mathrm{C}$ was dominated by a network structure with thin silicate streaks, whereas a more dense slag formation with readily discernible pores occurred at $1000{ }^{\circ} \mathrm{C}$.

- For both temperatures, accumulation of partially molten ash on char particle surface and in cracks was readily observed from app. $40 \mathrm{wt} \%$ char conversion.

- The observations of molten or partially molten material in single-pellet experiments qualitatively agree with calculated slag formation at full conversion, with app. $64 \mathrm{~mol} \%$ slag at low temperature and app. $90 \mathrm{~mol} \%$ at high temperature.

- Higher combustion temperature led to lower predicted viscosity, which promoted the morphological differences observed.

- Importantly, at single-particle level, ash formation around and in char particles did not inhibit fuel conversion at the different temperatures by mechanisms such as char encapsulation.

\section{ASSOCIATED CONTENT}

\section{S Supporting Information}

The Supporting Information is available free of charge on the ACS Publications website at DOI: 10.1021/acs.energyfuels.8b04294.

Linear fit for the different main ash-forming elements (PDF)

Animations of reconstructed 3D volumes (AVI)

\section{AUTHOR INFORMATION}

\section{Corresponding Author}

*E-mail: markus.brostrom@umu.se. Phone: +46 702955971.

\section{ORCID}

Anna Strandberg: 0000-0003-0895-3474

Nils Skoglund: 0000-0002-5777-9241

Markus Broström: 0000-0003-1095-9154

Notes

The authors declare no competing financial interest.

\section{ACKNOWLEDGMENTS}

Johannes Koestel at the X-ray facility of the Department of Soil and Environment, Swedish University of Agricultural Sciences, Sweden, is gratefully acknowledged for the X-ray microtomography analysis of the WS700 chars and for comments on the work. This research used the resources of the Advanced Light Source (ALS), at Lawrence Berkeley National Laboratory, Berkeley, California, which is a DOE Office of Science User Facility under contract no. DE-AC02-05CH11231 (ALS08232 T.A.L.). ALS Beamline 8.3.2 is acknowledged and we thank research scientist Dr Dula Parkinson for valuable assistance with the analyses at ALS. We also thank the facilities and technical support (Cheng Choo Lee) of the Umeå Core Facility for Electron Microscopy (UCEM) at the Chemical Biological Centre (KBC), Umeå University. Anders Rebbling is acknowledged for assistance with the combustion experiment in the domestic pellet boiler. The Swedish Research Council (grant 2014-5041) and Bio4Energy, a strategic research environment appointed by the Swedish government, are acknowledged for supporting this work.

\section{REFERENCES}

(1) Tao, G.; Lestander, T. A.; Geladi, P.; Xiong, S. Renewable Sustainable Energy Rev. 2012, 16, 3481-3506.

(2) Lestander, T. A. In Chemical Composition of Biomass; Dahlquist, E., Ed.; CRC Press/Balkema: Leiden, Netherlands, 2013; Vol. 3, pp $35-56$.

(3) Vassilev, S. V.; Baxter, D.; Andersen, L. K.; Vassileva, C. G. Fuel 2010, 89, 913-933.

(4) Vassilev, S. V.; Vassileva, C. G.; Song, Y.-C.; Li, W.-Y.; Feng, J. Fuel 2017, 208, 377-409.

(5) Monti, A.; Di Virgilio, N.; Venturi, G. Biomass Bioenergy 2008, 32, 216-223.

(6) Zevenhoven, M.; Yrjas, P.; Skrifvars, B.-J.; Hupa, M. Energy Fuels 2012, 26, 6366-6386.

(7) Tao, G.; Geladi, P.; Lestander, T. A.; Xiong, S. Renewable Sustainable Energy Rev. 2012, 16, 3507-3522.

(8) Kenney, K. L.; Smith, W. A.; Gresham, G. L.; Westover, T. L. Biofuels 2013, 4, 111-127.

(9) Sander, B. Biomass Bioenergy 1997, 12, 177-183.

(10) Baxter, L. L.; Miles, T. R.; Miles, T. R.; Jenkins, B. M.; Milne, T.; Dayton, D.; Bryers, R. W.; Oden, L. L. Fuel Process. Technol. 1998, 54, 47-78.

(11) Gilbe, C.; Öhman, M.; Lindström, E.; Boström, D.; Backman, R; Samuelsson, R.; Burvall, J. Energy Fuels 2008, 22, 3536-3543.

(12) Werther, J.; Saenger, M.; Hartge, E. U.; Ogada, T.; Siagi, Z. Prog. Energy Combust. Sci. 2000, 26, 1-27.

(13) Frandsen, F. J. Fuel 2005, 84, 1277-1294.

(14) Jensen, P. A.; Frandsen, F. J.; Dam-Johansen, K.; Sander, B. Energy Fuels 2000, 14, 1280-1285.

(15) Thy, P.; Lesher, C. E.; Jenkins, B. M. Fuel 2000, 79, 693-700.

(16) Knudsen, J. N.; Jensen, P. A.; Dam-Johansen, K. Energy Fuels 2004, 18, 1385-1399.

(17) Näzelius, I.-L.; Fagerström, J.; Boman, C.; Boström, D.; Öhman, M. Energy Fuels 2015, 29, 894-908.

(18) Boström, D.; Skoglund, N.; Grimm, A.; Boman, C.; Öhman, M.; Broström, M.; Backman, R. Energy Fuels 2012, 26, 85-93. 
(19) Wornat, M. J.; Hurt, R. H.; Yang, N. Y. C.; Headley, T. J. Combust. Flame 1995, 100, 131-143.

(20) Strandberg, A.; Thyrel, M.; Skoglund, N.; Lestander, T. A.; Broström, M.; Backman, R. Fuel Process. Technol. 2018, 176, 211220.

(21) Biswas, A. K.; Rudolfsson, M.; Broström, M.; Umeki, K. Appl. Energy 2014, 119, 79-84.

(22) Fagerström, J.; Steinvall, E.; Boström, D.; Boman, C. Fuel Process. Technol. 2016, 143, 204-212.

(23) Fagerström, J.; Näzelius, I.-L.; Gilbe, C.; Boström, D.; Öhman, M.; Boman, C. Energy Fuels 2014, 28, 3403-3411.

(24) Kinney, J. H.; Nichols, M. C. Annu. Rev. Mater. Sci. 1992, 22, $121-152$.

(25) MacDowell, A.; Parkinson, D.; Haboub, A.; Schaible, E.; Nasiatka, J.; Yee, C.; Jameson, J.; Ajo-Franklin, J.; Brodersen, C.; McElrone, A. Developments in X-Ray Tomography VIII; Stock, S. R., Ed. Proc. SPIE 2012, 8506, 850618.

(26) McElrone, A. J.; Choat, B.; Parkinson, D. Y.; MacDowell, A. A.; Brodersen, C. R. J. Vis. Exp. 2013, 74, 50162.

(27) Thy, P.; Jenkins, B. M.; Grundvig, S.; Shiraki, R.; Lesher, C. E. Fuel 2006, 85, 783-795.

(28) Bale, C.; Chartrand, P.; Degterov, S.; Eriksson, G.; Hack, K.; Mahfoud, R. B.; Melançon, J.; Pelton, A.; Petersen, S. Calphad 2002, $26,189-228$.

(29) Bale, C. W.; Bélisle, E.; Chartrand, P.; Decterov, S. A.; Eriksson, G.; Hack, K.; Jung, I. H.; Kang, Y. B.; Melançon, J.; Pelton, A. D.; Robelin, C.; Petersen, S. Calphad 2009, 33, 295-311.

(30) Kim, W.-Y.; Pelton, A. D.; Decterov, S. A. Int. J. Mater. Res. 2012, 103, 313-328.

(31) Grundy, A. N.; Jung, I.-H.; Pelton, A. D.; Decterov, S. A. Int. J. Mater. Res. 2008, 99, 1195-1209.

(32) Grundy, A. N.; Liu, H.; Jung, I.-H.; Decterov, S. A.; Pelton, A. D. Int. J. Mater. Res. 2008, 99, 1185-1194.

(33) Strandberg, A.; Holmgren, P.; Wagner, D. R.; Molinder, R.; Wiinikka, H.; Umeki, K.; Broström, M. Energy Fuels 2017, 31, 65076514.

(34) Sommersacher, P.; Kienzl, N.; Brunner, T.; Obernberger, I. Energy Fuels 2016, 30, 3428-3440.

(35) Chen, H.; Wang, F.; Zhang, C.; Shi, Y.; Jin, G.; Yuan, S. J. NonCryst. Solids 2010, 356, 2781-2785.

(36) Guntzer, F.; Keller, C.; Meunier, J.-D. Agron. Sustainable Dev. 2012, 32, 201-213.

(37) Steenari, B.-M.; Lindqvist, O. Biomass Bioenergy 1998, 14, 6776.

(38) Öhman, M.; Nordin, A. Energy Fuels 2000, 14, 618-624.

(39) Tran, K.-Q.; Iisa, K.; Hagström, M.; Steenari, B.-M.; Lindqvist, O.; Pettersson, J. B. Fuel 2004, 83, 807-812.

(40) Öhman, M.; Boström, D.; Nordin, A.; Hedman, H. Energy Fuels 2004, 18, 1370-1376.

(41) Davidsson, K.; Steenari, B.-M.; Eskilsson, D. Energy Fuels 2007, 21, 1959-1966.

(42) Boman, C.; Boström, D.; Öhman, M. European Biomass Conference \& Exhibition: 02/06/2008-06/06/2008, 2008; ETARenewable Energies, 2008; pp 1514-1517.

(43) Wang, L.; Becidan, M.; Skreiberg, Ø. Energy Fuels 2012, 26, 5917-5929.

(44) Lind, T.; Kauppinen, E. I.; Hokkinen, J.; Jokiniemi, J. K.; Orjala, M.; Aurela, M.; Hillamo, R. Energy Fuels 2006, 20, 61-68.

(45) Broström, M.; Kassman, H.; Helgesson, A.; Berg, M.; Andersson, C.; Backman, R.; Nordin, A. Fuel Process. Technol. 2007, 88, 1171-1177.

(46) Kassman, H.; Bäfver, L.; Åmand, L.-E. Combust. Flame 2010, 157, 1649-1657.

(47) Sommersacher, P.; Kienzl, N.; Brunner, T.; Obernberger, I. Energy Fuels 2015, 29, 6734-6746.

(48) Qu, Z.; Steinvall, E.; Ghorbani, R.; Schmidt, F. M. Anal. Chem. 2016, 88, 3754-3760.

(49) Fatehi, H.; Schmidt, F. M.; Bai, X.-S. Combust. Flame 2018, 196, 351-363. 